\title{
Por uma etnografia para a internet: transformações e novos desafios
}

\section{For an ethnography to the internet; changes and new challenges}

\author{
Entrevista com CHRISTINE HINE* \\ University of Surrey, Department of Sociology. Guildford, Reino Unido \\ por BRUNO CAMPANELLA**
}

Universidade Federal Fluminense, Programa de Pós-Graduação em Comunicação. Niterói-RJ, Brasil

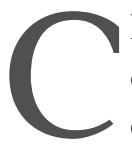

HRISTINE HINE É professora titular do Departamento de Sociologia da University of Surrey, no Reino Unido. Foi presidente da Associação Europeia para o Estudo da Ciência e Tecnologia de 2004 a 2008. Possui publicações sobre metodologia de pesquisas na internet, com um foco particular na etnografia, incluindo os livros Virtual ethnography (2000), Virtual methods (2005) e o mais recente Ethnography for the internet (2015).

Em setembro de 2015 participou do Seminário Internacional Etnografia e Consumo Midiático: Novas Tendências e Desafios Metodológicos, realizado na Universidade Federal Fluminense, ocasião em que surgiu o convite para a entrevista à revista MATRIZes.

Em suas reflexões, Hine atualiza algumas das principais discussões presentes em seus primeiros trabalhos, fala dos novos desafios trazidos por uma internet que permeia cada vez mais o cotidiano do indivíduo contemporâneo, conta um pouco de suas impressões acerca dos usos da internet no Brasil e oferece conselhos valiosos para quem está iniciando pesquisas na área.

MATRIZes: Quando publicou Virtual ethnography (2000), você propôs que havia dois modos de ver a internet: como cultura e como artefato cultural. Acredita que essa nítida divisão é ainda proveitosa?

Christine Hine: Em 2000, tomei a decisão estratégica de destacar dois aspectos inter-relacionados da internet que sentia importantes considerar ao desenvolver uma abordagem metodológica para entender a internet. $\mathrm{O}$ primeiro

\footnotetext{
* Professora titular do Departamento de Sociologia da University of Surrey, no Reino Unido. Autora de Ethnography for the internet (Bloomsbury Publishing, 2015), entre outras obras.

** Professor do Programa de Pós-Graduação em Comunicação da Universidade Federal Fluminense. E-mail: brunocampanella@yahoo. com
} 
aspecto, a internet como cultura, enfatizava que a internet era um espaço cultural onde as pessoas estavam participando de interações e atividades relevantes para elas em determinado nível e deveria, por isso, também ter interesse para a ciência social. Naquela época, apenas começávamos a abandonar uma percepção amplamente difundida, tanto dentro quanto fora da academia, de que as atividades on-line eram, de certo modo, muito limitadas para contar como atividades sociais reais. Era importante apoiar a reivindicação da significância cultural dos eventos on-line, embora sem assumir que eles pudessem prever que forma aquelas atividades iriam tomar ou qual seria sua importância sociocultural. O segundo aspecto que quis destacar, a internet como artefato cultural, deriva de minhas origens nos Estudos da Ciência e Tecnologia (ECT). Nesse campo, somos sensíveis à ideia de que as tecnologias são intrinsecamente sociais - os ECT defendem que nossas experiências e expectativas sobre as tecnologias são moldadas por processos sociais que colaboram, fazendo essas tecnologias terem sentido para grupos específicos de pessoas. $\mathrm{Na}$ época que escrevia, ocorria uma quantidade considerável de discussões sobre a internet, nos diálogos e nos meios massivos, e parecia importante ressaltar que essa ampla discussão de ideias sobre o que a internet era ajudava a moldar o que as pessoas faziam com essa ferramenta e o que o seu uso significava para elas. A distinção funciona como um dispositivo heurístico válido, por nos lembrar de levar em conta tanto o que acontece on-line, em seus próprios termos, quanto as amplas circulações e reinterpretações das atividades on-line ao longo de outros domínios culturais. Os dois aspectos da internet, entretanto, não devem ser encarados como separáveis em qualquer modo evidente eles se nutrem mutuamente.

Avançando no tempo até a internet contemporânea, acredito que a divisão heurística ainda é útil para nos lembrar dos complexos processos de modelagem social que tornam a internet o que é atualmente. Entretanto, cada vez mais a internet não é particularmente significativa para as pessoas como um artefato cultural que elas se sintam confortáveis em debater. A internet ainda se mantém como um artefato cultural em alguns debates, no entanto, as pessoas, com mais frequência do que falam sobre a internet, falam sobre redes sociais específicas ou aplicativos que são relevantes para elas por alguma razão. Nós temos, crescentemente, perdido de vista a internet como um artefato cultural, na medida em que ela se torna uma infraestrutura tácita que favorece as plataformas sobre as quais falamos com mais frequência.

MATRIZes: Desde o lançamento daquele livro (Virtual ethnography), quinze anos atrás, a internet mudou bastante. Pode-se dizer que ela tornou- 
-se mais social e mais conectada. Essas mudanças têm um impacto no modo como fazemos etnografia na internet? Se sim, em qual aspecto?

Hine: Gostaria de utilizar o termo permeação ${ }^{1}$ para captar a natureza dessa mudança. Nenhum desenvolvimento individual conduziu essa mudança, mas os fatores que a promoveram incluem: a tendência dos sites de rede social a serem usados para a comunicação com pessoas que conhecemos por outros meios; a normalização do e-comércio como um meio para comprar praticamente qualquer coisa; a crescente dependência dos governos e instituições em relação às bases de dados e transações digitais, não como uma alternativa para outros meios de realizar negócios, mas como um componente indispensável de fazer todo tipo de negócio; o surgimento do acesso amplo à internet móvel por meio dos smartphones e Wi-Fi ubíquo.

Todos esses fatores inter-relacionados nos conduziram para uma internet que agora, muito mais que nos anos 1990, permeia completamente aspectos centrais da vida cotidiana para grande parte da população - mas, é claro, nem toda. A amplitude dessa permeação coloca um desafio para as abordagens etnográficas da internet. Agora, mais do que nunca, tornou-se difícil justificar uma separação a priori da internet como um espaço independente do campo de pesquisa. Muitas questões de pesquisa que queremos indagar implicam explorar dinâmicas culturais além de um único espaço on-line, para achar outras extensões culturais nas quais aquelas atividades on-line estão permeadas e adquirem significância. Foi sempre assim, em alguma medida - a dinâmica cultura/artefato cultural que discuti antes significava que estávamos sempre realizando um corte mais ou menos artificial se escolhíamos estudar um único espaço on-line como campo de pesquisa. Agora, entretanto, tornou-se mais difícil ainda justificar estes estudos exclusivamente on-line, em muitos casos.

MATRIZes: Em seu último livro, Ethnography for the internet (2015), você dificilmente usa o termo virtual, como utilizou em vários de seus trabalhos anteriores, como Virtual etnography (2000) ou Virtual methods (2005). Existe uma razão para isso? Associado a essa questão, faz sentido usar termos como (etnografia) on-line, (etnografia) virtual ou mesmo net(nografia) como um modo de diferenciação da etnografia tradicional?

Hine: O virtual era um termo útil para descrever uma ampla comunidade de pesquisadores que se esforçava para encontrar soluções para questões semelhantes envolvendo nossa capacidade de dar sentido à internet; em certa medida isso ainda é verdadeiro: a palavra constitui um ponto de encontro para reunir pessoas com interesses parecidos e apreender algumas preocupações relacionadas. Entretanto, vejo-o como cada vez mais inútil à luz de uma
1. Embedding, no original (N. do T.). 
internet que permeia nosso cotidiano, e a crescente dificuldade de distinguir os estudos que envolvem a internet de outros tipos de etnografia. Se usar algum dos termos comuns on-line, virtual ou net implica que isso é, de algum modo, um tipo fundamentalmente diferente de etnografia, então prefiro evitar o termo. Vejo uma continuidade de princípios metodológicos entre os tipos de etnografia que podemos aplicar à internet e os tipos que usamos em qualquer outro domínio cultural, embora algumas das técnicas possam diferir. Não creio que usar um termo específico para a etnografia envolvendo a internet é particularmente útil, pois promove um afastamento dos princípios metodológicos mais gerais da etnografia.

MATRIZes: Em Ethnography for the internet (2015), você propõe que a internet deve ser entendida como um fenômeno permeado, incorporado e cotidiano (no original, a internet E3: "embedded, embodied e everyday"). Você poderia explicar o que significa isso, e como usar essa abordagem na construção de uma estratégia de pesquisa?

Hine: Embora, como disse, não deseje distinguir a etnografia envolvendo a internet de outras formas de etnografia, é correto dizer que aplicar uma abordagem etnográfica à internet requer alguns tipos específicos de criatividade, de modo a ser capaz de detalhar os modos pelos quais as atividades on-line produzem sentido. Os etnógrafos são pessoas flexíveis que desenvolvem seus métodos em resposta aos contextos em que se encontram e cada estudo é, por isso, único em sua abordagem. Entretanto, é importante aprender um do outro, e podemos com frequência ter alguma inspiração a partir de abordagens que funcionam em outros contextos semelhantes. Os três Es identificam aspectos da etnografia que se alinham com estratégias metodológicas específicas em alguns estudos que conduzi que, cada um de algum modo, conectaram o on-line e o off-line e tentaram refletir sobre como a internet produz sentido. Ao identificar algumas características bastante gerais da internet conforme me defrontava com ela e conectá-las a estratégias metodológicas, esperava oferecer a outros etnógrafos uma estrutura para identificar abordagens que possam ser úteis a eles.

A internet permeada adquire seu significado nos contextos com os quais ela está associada. As conexões múltiplas e imprecisas entre on-line e off-line, e as diversas estruturas de produção de significado que usamos para construir sentido do que acontece on-line, com frequência nos levam a noções de campo móveis, conectivas e multiespaciais. Elas também incitam reflexões sobre a responsabilidade que o pesquisador de campo assume ao delinear seu objeto específico de estudo, escolhendo estudar alguns aspectos da internet incorporada mais do que outros. 
A internet incorporada enfatiza que utilizamos a internet como seres socialmente situados, sujeitos a várias limitações de nossas ações, e reagindo com emoções, conforme forjamos uma perspectiva individualizada sobre a internet, a partir dos links específicos que seguimos e sites que encontramos. Esse aspecto da internet estimula as abordagens reflexivas e autoetnográficas que se concentram sobre o sentimento de navegar na variedade de camadas de experiência ao longo das diferentes mídias e que refletem em que medida a experiência do etnógrafo pode esclarecer aspectos tácitos da experiência daqueles que estudamos.

A cotidianidade da internet reforça a tendência dessa ferramenta e das plataformas individuais on-line em serem tratadas como infraestruturas não percebidas na maior parte do tempo e apenas raramente tematizadas em discussão específica. Pode ser bastante útil para o etnógrafo assumir uma perspectiva crítica, tanto sobre a despercebida internet cotidiana, quanto sobre a internet tematizada. O que assumimos como evidente quando deixamos de notar a internet em nossas vidas? Quais ocasiões e momentos em que discutimos a internet: quem está explicando a internet, para quem e com que objetivo?

MATRIZes: Você acredita que é possível (ou desejável) misturar métodos de análises de big data com a etnografia. Se sim, como?

Hine: É certamente possível combinar métodos e creio que muitas vezes é também desejável. Existem agora tantos modos de agregar e visualizar dados on-line que parece quase inaceitável que os etnógrafos não os utilizem. Esses métodos não são, afinal, alheios à tradição da etnografia, que tem com frequência mesclado um rico e evocativo relato a um mapa ou um diagrama para colocar a narrativa em um contexto. Quando a etnografia possui um componente on-line, grande parte dos dados tem origem digital, portanto, isso irá tornar muitas vezes possível explorar padrões nos dados por meio do uso de ferramentas preexistentes ou pelo desenvolvimento de uma solução específica. Essa exploração de padrões pode ser utilizada para dirigir a etnografia a aspectos interessantes do campo de pesquisa, para produzir a antecipação de questões ou para contextualizar as narrativas. Os big data oferecem uma perspectiva poderosa a campo, podendo gerar percepções etnográficas específicas. Entretanto, há razões para ser cauteloso a respeito de quanto eles e a etnografia representam uma combinação perfeita, entre as quais está o fato de os big data serem, com frequência, captados de uma plataforma de cada vez; e o etnógrafo deseja muitas vezes mover-se entre plataformas, do on-line ao off-line. É importante não ficarmos seduzidos demais pela aparente capacidade que eles têm de mostrar uma imagem grandiosa. 
MATRIZes: Quando esteve no Brasil em setembro de 2015, você fez uma apresentação no Seminário Internacional Etnografia e Consumo Midiático organizado na Universidade Federal Fluminense e também tomou parte em várias atividades acadêmicas, tanto com estudantes de pós-graduação quanto com pesquisadores consolidados. De tudo que você viu e ouviu, aprendeu alguma coisa interessante sobre as práticas de mídia usuais no Brasil que você não tenha visto no Reino Unido?

Hine: Tive conversas realmente estimulantes durante a viagem, aprendi muitas coisas sobre o interessante trabalho feito em etnografia da mídia no Brasil e sobre o panorama da mídia brasileira. Em algumas dessas conversas, começamos a descobrir diferenças entre as práticas midiáticas no Brasil e aquelas que conheço do Reino Unido. A primeira impressão sugere que o Facebook é mais dominante no contexto brasileiro, enquanto no Reino Unido há possivelmente maior diversidade nas plataformas on-line utilizadas: algumas pessoas têm uma preferência pelos fóruns on-line anônimos, em vez da exposição mais aberta do Facebook. Parece haver algumas interessantes linhas de comparação para indagar sobre os modos pelos quais as pessoas nos países gerem o sentido de obrigatoriedade social de ser ativo no Facebook e os modos pelos quais as pessoas manejam as fronteiras entre o trabalho e o lazer e entre os diferentes círculos sociais a que pertencem. Também fiquei bastante impressionada com uma cultura da selfie no Brasil, mais do que percebo no Reino Unido - porém, isso pode ser porque eu fiquei no Rio e observei o comportamento turístico em Copacabana! Não colocaria demasiada ênfase nessas primeiras impressões, mas existem algumas possíveis diferenças intrigantes nos modos pelos quais os dois países se envolvem em diversas plataformas on-line. Estas são o tipo de comparação que o estudo Global social media impact de Daniel Miller estuda com profundidade, e seria muito interessante ver o que tais dados indicam sobre a mesma comparação.

MATRIZes: Quais conselhos você daria para um pesquisador que está começando sua etnografia na internet? Que tipo de leitura você sugeriria?

Hine: Meu conselho é ler amplamente a literatura acadêmica, on-line e nos meios massivos - mas questionar tudo! É importante não presumir que sabemos o que a internet é e o que as pessoas fazem com ela. A leitura ampliada deve ser uma ajuda para a imaginação etnográfica, faz alguém ver quais tipos dentro da rica variedade são possíveis, sugerindo direcionamentos produtivos e técnicas a empregar. Nosso campo possui hoje algumas revisões e manuais realmente bons, assim como monografias individuais, e estes podem ser utilizados para informações proveitosas. Os textos impressos tradicionais, 
por outro lado, têm dificuldade em manterem-se atualizados em um território de rápidas mudanças. Quando o campo de pesquisa, ou parte dele, está on-line, pode ser bastante desafiador resolver dificuldades técnicas e desenvolver meios adequados para armazenar e investigar dados, e grande parte de nós não têm as competências técnicas para fazer isso do zero. Muitas destas informações não são inseridas nos manuais didáticos a tempo de serem úteis, assim, pode ser válido participar de discussões on-line com acadêmicos que pesquisam o mesmo assunto. A lista de e-mails da Association of Internet Researchers, por exemplo, contém uma riqueza de conhecimento e oferece um lugar bastante útil para troca de aconselhamento atualizado. Os blogs e wikis de pesquisa oferecem outra valiosa fonte de informações sobre como outros pesquisadores trabalham. A Digital Methods Initiative de Richard Rogers possui algumas ferramentas valiosas para tirar proveito de dados propriamente digitais e complementar observações não estruturadas. O site Ethnography Matters hospeda informações particularmente úteis e importantes sobre os desenvolvimentos no campo. Todas essas formas de leitura, compartilhamento de habilidades e construção de redes são muito úteis para a inspiração mas, em seguida, é importante ir além, mergulhar no campo e abrir-se de modo a desafiar as próprias concepções prévias. $\mathbf{M}$

\section{REFERÊNCIAS}

HINE, C. Ethnography for the internet: embedded, embodied and everyday. Huntingdon, GBR: Bloomsbury Publishing, 2015. . (ed.). Virtual methods: issues in social research on the internet. New York: Berg Publishers, 2005. . Virtual ethnography. London: Sage, 2000. 
